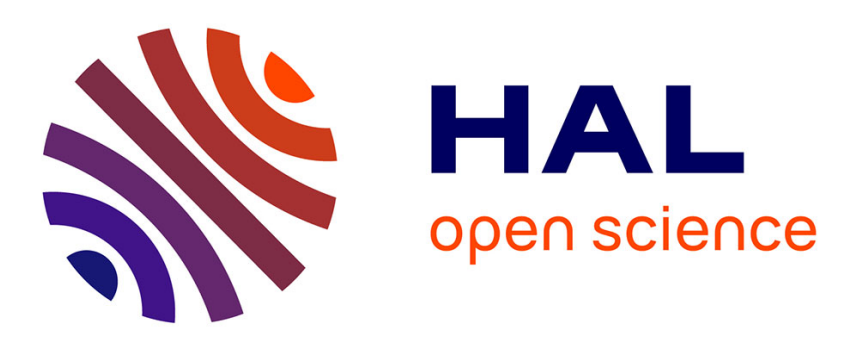

\title{
Introduction to a Model for Life Cycle Optimisation of Industrial Equipment
}

\author{
Daniele Cerri, Valerio Contaldo, Marco Taisch, Sergio Terzi
}

\section{To cite this version:}

Daniele Cerri, Valerio Contaldo, Marco Taisch, Sergio Terzi. Introduction to a Model for Life Cycle Optimisation of Industrial Equipment. 11th IFIP International Conference on Product Lifecycle Management (PLM), Jul 2014, Yokohama, Japan. pp.193-200, 10.1007/978-3-662-45937-9_20 . hal01386497

\section{HAL Id: hal-01386497 https://hal.inria.fr/hal-01386497}

Submitted on 24 Oct 2016

HAL is a multi-disciplinary open access archive for the deposit and dissemination of scientific research documents, whether they are published or not. The documents may come from teaching and research institutions in France or abroad, or from public or private research centers.
L'archive ouverte pluridisciplinaire HAL, est destinée au dépôt et à la diffusion de documents scientifiques de niveau recherche, publiés ou non, émanant des établissements d'enseignement et de recherche français ou étrangers, des laboratoires publics ou privés. 


\title{
Introduction to a Model for Life Cycle Optimisation of Industrial Equipment
}

\author{
Daniele Cerri $^{1}$, Valerio Contaldo ${ }^{1}$, Marco Taisch ${ }^{1}$, Sergio Terzi ${ }^{2}$ \\ ${ }^{1}$ Politecnico di Milano, Department of Management, Economics and Industrial Engineering \\ Piazza Leonardo da Vinci, 20133, Milano, Italy \\ daniele.cerri@polimi.it \\ valerio.contaldo@mail.polimi.it \\ marco.taisch@polimi.it \\ ${ }^{2}$ Università degli Studi di Bergamo, Department of Engineering, Viale Marconi 5, 24044, \\ Dalmine (Bergamo), Italy \\ sergio.terzi@unibg.it
}

\begin{abstract}
In this evolving context, to pursue a Life Cycle approach, realizing green products / system at the less cost of ownership, can be a strategic key for Advanced Countries companies to compete and survive in the global market. Aim of this paper is to present a model for Life Cycle Optimisation, considering both economic and environmental dimensions. At the end of the paper a first application of this model will be presented.
\end{abstract}

Keywords: Life Cycle Assessment, LCA, Life Cycle Costing, LCC, Life Cycle Optimisation, Life Cycle Simulation.

\section{Introduction}

During the last years, the operating context of global companies has been dramatically changed due to several reasons, often mutually related.

Firstly, globalization pushed the industrial companies of Advanced Countries (European, American and Japanese) to face the ones of emerging countries (BRICS) in a "flat" world [1], where global competitors start from the same line. In this context, Advanced Countries companies are forced to face the low cost pressure of emerging countries.

At the same time, also the customers' behaviour changed. Global customers demand for personalized solutions [2] at the lowest total cost of ownership, more reliable systems, less polluting equipment, less consuming plants / facilities, greener products, etc. 
Environmental consciousness is more and more felt, also due to the imposition of regulations and normative. In fact, national and international institutions are strictly regulating the environment, like Kyoto protocol or the tons of EU Directives.

In this evolving context, to pursue a life cycle approach, considering both economic and environmental dimensions, and realizing green products / systems at the less cost of ownership, can be a strategic key for Advanced Countries companies to compete and survive in the global market.

Designers and system engineers are the main involved actors to pursue a life cycle approach, due to their influence on product life cycle costs and environmental impacts. Different studies like [3], [4], [5] and [6] estimates how designers, during the design phase, fix about $65 \%-85 \%$ of the total costs. The same consideration, about product life cycle environmental impacts, is reported in [7].

The aim of this paper is to propose a first model to support designers and system engineers in the creation and identification of best life cycle oriented concept. The paper is so organized: in Section 2 a brief state of the art of Life Cycle Optimisation will be presented. In Section 3 the conceptual framework of the model will be explained, while in Section 4 first results are reported. Finally, in the Section 5 , conclusions will end the paper.

\section{State of the Art}

To pursue a Life Cycle approach, in terms of costs and environmental impacts, it is necessary to study and depth two methodologies: Life Cycle Costing (LCC) and Life Cycle Assessment (LCA). Both the methodologies are well known in literature, being developed by the $60 \mathrm{~s}$.

Life Cycle Costs are described as "cradle-to-grave" costs summarized as an economic model of evaluating alternatives for equipment and projects [8]. [9] defined LCC as the total cost of acquiring and utilizing a system over its entire life span, in other words LCC is the total cost of procurement and ownership. More detailed definitions are proposed by [10] - Life cycle cost is the total cost of ownership of machinery and equipment, including its cost of acquisition, operation, maintenance, conversion, and/or decommission - and [11] - LCC are summations of cost estimates from inception to disposal for both equipment and projects as determined by an analytical study and estimate of total costs experienced in annual time increments during the project life with consideration for the time value of money.

Life Cycle Assessment is described as a technique to assess environmental impacts associated with all the stages of a product's life from-cradle-to-grave [12]. [13] instead stated LCA as a methodological framework for estimating and assessing the environmental impacts attributable to the life cycle of a product. 
The LCA process is a systematic, phased approach and consists of four components: goal definition and scoping, inventory analysis, impact assessment and interpretation. This process is described in the standard "ISO 14040 Environmental Management - Life Cycle Assessment - Principles and Framework" [14].

The above described methodologies allow only an evaluation / estimation of costs and environmental impacts along the product lifecycle, comparing few alternatives. Therefore, to be more effective in the product development, it is necessary to explore a huge number of alternatives - if it is possible all the ones -, in order to find the best solution. The idea is to apply something similar to Set Based Concurrent Engineering (SBCE), exploring and testing several concepts in parallel. The results of the alternatives are presented in different forms like trade-off curves, checklist, etc., in order to support the decision [15] [16].

To pursue this approach, LCC and LCA methodologies are not sufficient. Therefore it is necessary to support them, applying methods and techniques so as to explore the different alternatives, evaluating costs, environmental impacts and technical performances along the whole life cycle.

Analysing the literature, two main areas are identified: optimisation and simulation. Within our group, two works try to explore these areas. In [17], 79 contributions from the last 15 years ( 39 related to LCC methodology and 40 related to LCA methodology) are analysed, in order to find which types of optimisation method are used and if costs and environmental impacts were together optimised, or at least both considered. In [18] authors analysed the state of the so called Life Cycle Simulation (LCS). 43 contributions from the last 15 years are analysed, in order to classify the field.

From these analyses some gaps / discordances came to light. In literature, optimisation methods are applied in few contributions, while the majority used simply the life cycle methodologies for an evaluation, using in some cases software (mainly applied to LCA). Moreover, using a multi-objective optimisation there is not a unique solution, obviously, but a set of optimal solutions, due to the tradeoffs incurred between the different objectives. Therefore the decision makers have to choose the best solution for their customers within a set of optimal solutions.

In simulation area, instead, there are several discordances in the definition of lifecycle boundaries and which should be the inputs and outputs of the simulation. Moreover, different tools are used to perform a simulation of the product life cycle, from spread-sheets, mathematical software, and programming languages to specialist computational packages. Found these gaps / discordances, the objective of the paper is to define a model for Life Cycle Optimisation, considering the literature analysed. In the next section the Conceptual Framework behind Life Cycle Optimisation model will be presented. 


\section{Conceptual Framework of Life Cycle Optimisation}

In the light of the deficiencies / discordances shown in the previous section, the aim of the paper is to show the develop of an integrated, structured and robust model, completed by methods and tools, to support designers and system engineering during the concept phase, in order to create and identify the optimal life cycle oriented concept, in terms of economic and environmental dimensions. The conceptual framework of the model is reported in this Section (see Fig. 1).

\begin{tabular}{|c|c|c|c|c|c|c|}
\hline $\begin{array}{c}\text { Problem } \\
\text { definition and } \\
\text { Modeling }\end{array}$ & $\longrightarrow$ & $\begin{array}{c}\text { Alternatives' } \\
\text { Exploration }\end{array}$ & $\longrightarrow$ & $\begin{array}{c}\text { Analysis of } \\
\text { Solutions' } \\
\text { Robustness }\end{array}$ & $\longrightarrow$ & $\begin{array}{c}\text { Decision } \\
\text { Making }\end{array}$ \\
\hline
\end{tabular}

Fig. 1. Conceptual Framework of Life Cycle Optimisation model

The framework is composed of four main blocks. In the first one, "Problem definition and Modeling", the problem will be defined, in order to determine which costs, environmental impacts and performances take into account. This allows understanding which data and information are necessary to model the problem. The output of this block is all the possible concepts.

In the second one, “Alternatives' Exploration", methods or techniques will be applied, in order to narrow the initial number of concepts, selecting a set of optimal ones. As previously discussed, the most used optimisation method is genetic algorithm, that is very fitting with multi-objective problems, like the minimization of costs and environmental impacts generated along the product life cycle.

In the third one, "Analysis of Solutions' Robustness", methods or techniques will be used, in order to evaluate the robustness of the solutions changing some parameters. Analysing the literature, a method like Life Cycle Simulation or Sensitivity Analysis could be useful for the purpose. The output will be a set of optimal and robust concepts.

Finally, in the last block, "Decision Making", methods or techniques will be applied, in order to choose the more appropriate life cycle oriented concept for the customers. Having a multi-objective problem, the output at the end of the third block will be a set of optimal concepts. To weight the objectives, satisfying customer's requirements and needs, allow finding the more appropriate life cycle oriented concept for itself. Methods like Multi-Criteria Decision Making (MCDM) are effective to return the best concept.

In the next Section a first application of the model will be shown. 


\section{First Application}

The conceptual framework developed and described in the previous section has been applied to a real case study: we have performed the Life Cycle Optimisation of an engine assembly line.

\section{A. Problem Definition}

In particular, we have considered a fraction of the line composed by five stations. As shown in Fig.2, each station forming the analysed assembly line has been actually provided with a set of available alternatives: we have considered 16 station alternatives ( 2 alternatives for the first station, 4 alternatives for the second station, and so on, where "aut", "saut" and "man" stand for automatic, semiautomatic and manual, respectively), but the set of available alternatives to be evaluated during the optimisation can be easily extended. Taking up the definitions of Cartesian product and cardinality, since the line is formed by 5 stations and the number of alternatives each station is provided with is known, the number of available line alternatives can be evaluated as follows:

$$
\left|S_{1} \times S_{2} \times S_{3} \times S_{4} \times S_{5}\right|=|2 \times 4 \times 2 \times 4 \times 4|=256
$$
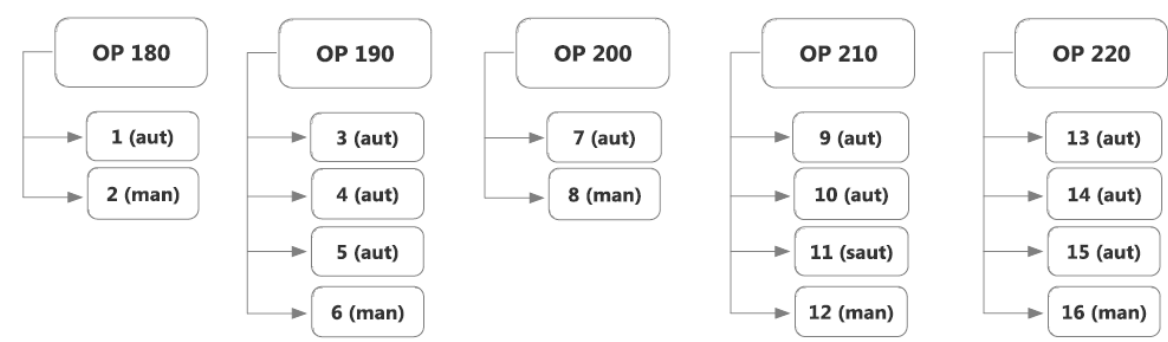

Fig. 2. Station code and corresponding station alternatives.

\section{B. Alternatives' Exploration and Analysis of Solutions' Robustness}

The aim of the analysis has been finding the optimal line configuration or line alternative. From an economical point of view, the "optimal" line configuration is the one that minimizes life cycle costs; therefore we have performed a singleobjective optimisation:

$$
\min L C C_{\text {tot }}=\min \sum_{s=1}^{5} L C C_{s}
$$

where LCCs represents the lifecycle cost of s-th station that forms the line analysed. Being a single-objective problem, in this particular case the Decision Making block has not been implemented. Moreover, Alternatives' Exploration and Analysis of Solutions' Robustness have been realized in one single step, combining 
simulation and optimisation. In particular, in the proposed model the life cycle behaviour of a station is simulated by means of Discrete Event Simulation (DES). Therefore, allowing the user to replicate the station model an arbitrary number of times, it is possible to create the model of any industrial equipment (e.g. an assembly line or a production line) and simulate its costs and environmental impacts from a life cycle perspective. Optimisation by means of genetic algorithm is also implemented to identify the values of each station's input parameters which permit to minimize a suitable objective function: processing simulation outputs in an iterative way, the optimisation method eventually finds the "optimal" line configuration. Adopting simulation-based optimisation allows to get significant information during the early design stages: simulation permits to cover the whole life cycle perspective, while optimisation ensures that final results - in terms of input parameters - denote the selection of best elements (with regard to some criteria specified in the objective function) from some set of available alternatives. The implementation of this model is realized taking advantage of the potentialities

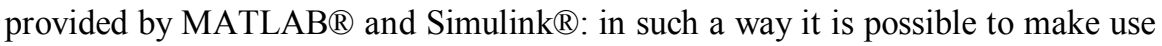
of one single software tool - Simulink is integrated with MATLAB - to combine optimisation with simulation.

In Fig. 3 the outward appearance of the "station block" is presented, i.e. the Simulink block that implements the simulation of the life cycle behaviour of a manufacturing plant's station. In the right side of the block it is possible to recognize the output ports that allow extracting the signals generated within the block. In such a way these output signals are made available for visualization and postprocessing analysis. Particular attention has been paid to realize an in depth modelling of the station's maintainability, since at equipment and system level maintainability has a great influence on reliability and availability; it is thus an important parameter in the optimisation of availability and life cycle costs.

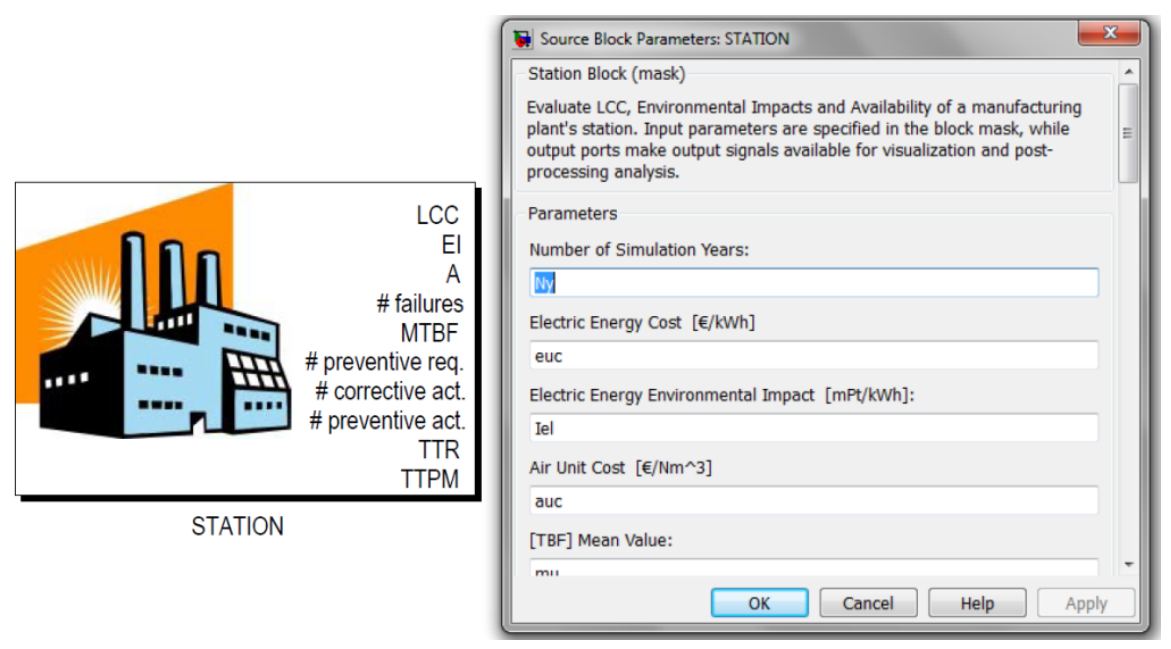

Fig. 3. Station block and its mask: SimEvents ${ }^{\circledR}$ block of industrial equipment's station. 


\section{Results}

In Fig. 4 results are presented. The first graph of Fig. 4 shows the convergence of the genetic algorithm to the optimal solution; the algorithm stopped according to the selected stopping condition, i.e. on the basis of the evaluation of the weighted average relative change in the fitness function value. The second graph provides the vector entries of the individual with the best fitness function value, i.e. the number of the selected alternative of each station forming the line. Even if these results refer to the optimal solution from an economical perspective, the value of its environmental impacts has been kept under control, so as to satisfy environmental requirements too.

Results have been validated and the model has been regarded as an interesting support tool during the early stages of the detailed design.
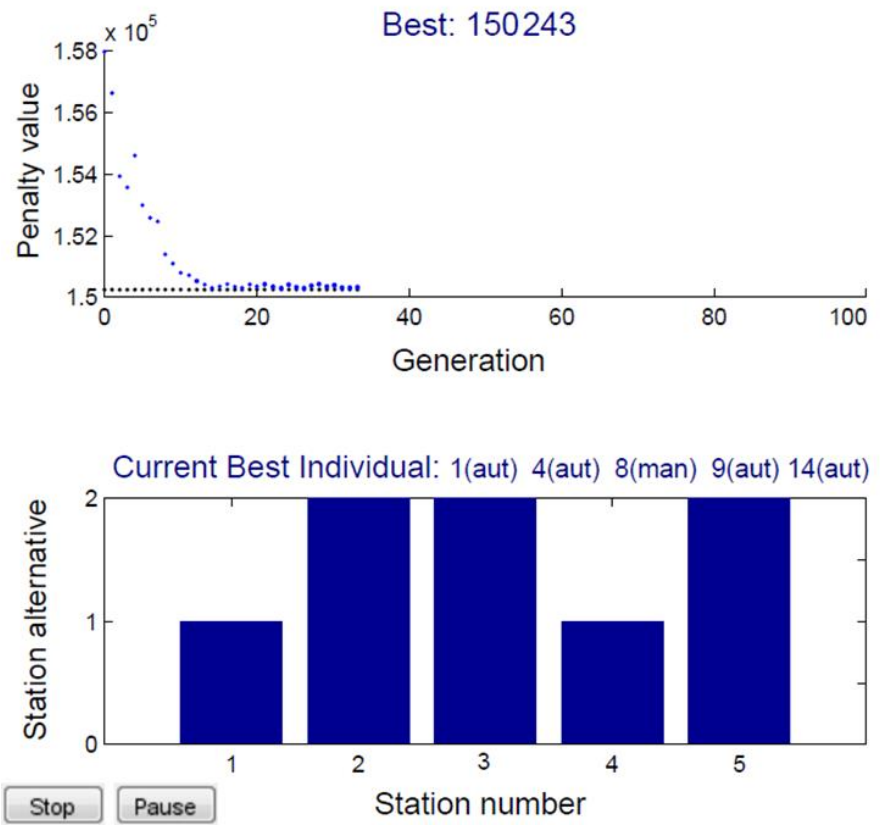

Fig. 4. Results.

\section{Conclusions}

In this paper the aim is to present a model for Life Cycle Optimisation of industrial equipment. Introduction (Section 1) points out the context where Advanced Countries companies operate, highlighting how to pursue a Life Cycle approach can be a strategic key to compete and survive in the global market. Moreover, the 
main actors involved in Life Cycle approach are identified in designers and system engineers.

Analysing state of the art about life cycle methodologies (Section 2), two main methodologies are identified: Life Cycle Costing and Life Cycle Assessment. However, these methodologies are not sufficient to explore a huge numbers of alternatives. The idea is to apply something similar Set Based Concurrent Engineering, exploring different concepts in parallel. To pursue this approach it is necessary to support LCC and LCA, applying methods and techniques so as to explore the different alternatives, evaluating costs, environmental impacts and technical performances along the whole life cycle. In literature two main areas are identified: optimisation and simulation. Analysing these areas, gaps / discordances came out.

In the light of these deficiencies, a conceptual framework of Life Cycle Optimisation model is presented (Section 3), and in Section 4 a first application is shown.

Designers and system engineers of the first application have appreciated this model, because it allows them a fast exploration of a huge number of concepts.

However, further analyses are necessary to improve the proposed model. First of all, a more accurate literature analysis is necessary, in order to define all the existing methods / techniques, to classify them and to select the more appropriate one for the model.

Finally, a new application cases will be searched, to test in depth and to make the most general possible the model proposed. In particular, a comparison between an application case in B2B (Business-to-business) market and another one in B2C (Business-to-customer) market could be really interesting, in order to understand if a different approach in Life Cycle Optimisation exists.

Acknowledgments. This work was partly funded by the European Commission through the Linked Design Project (FoF-ICT-2011.7.4: Digital factories: Manufacturing design and product lifecycle management, http://www.linkeddesign.eu/). The authors wish to acknowledge their gratitude and appreciation to the rest of the project partners for their contributions during the development of various ideas and concepts presented in this paper.

\section{References}

1. Friedman, T. (2005): "The World Is Flat: A Brief History of the Twenty-First Century". Farrar, Straus and Giroux.

2. McCarthy, I.P. (2004): "Special issue editorial: the what, why and how of mass customization". Production Planning \& Control 25 (4) 
3. Munro, A.S. (1995): "Let's roast engineering sacred cows". Machine Design 67 (3)

4. Romm, J.J. (1994): "Lean and Clean Management: How to Boost Profits and Productivity by Reducing Pollution". New York, Kodansha International

5. Dowlatshahi, S. (1996): "The role of logistics in concurrent engineering". Journal of Production Economics 44

6. Blanchard, B. S. (1991): "Design To Cost, Life-Cycle Cost". 1991 Tutorial Notes Annual Reliability and Maintainability Symposium, available from Evans Associates, 804 Vickers Avenue, Durham, NC 27701

7. Rebitzer, G., Ekvall, T., Frischknecht, R., Hunkeler, D., Norris, G., Rydberg, T., Schmidt, W. P., Suh, S., Weidema, B.P., Pennington, D.W. (2004): "Life cycle assessment Part 1:Framework, goal and scope definition, inventory analysis, and applications". Environment International 30 (5)

8. Barringer, H. P. (2003): “A Life Cycle Cost Summary". ICOMS 2003

9. Elmakis, D., Lisnianski, A. (2006): "Life cycle cost analysis: Actual problem in industrial management". Journal of Business Economics and Management $7,5-8$

10. Society of Automotive Engineers (SAE) (1999): "Reliability and Maintainability: Guideline for Manufacturing Machinery and Equipment". M-110.2, Warrendale, PA (1999)

11. Landers, R. R. (1996): "Product Assurance Dictionary". Marlton Publishers, 169 Vista Drive, Marlton, NJ 08053

12. Scientific Applications International Corporation (SAIC) (2006): "Life Cycle Assessment: Principles and Practice". Technical Report

13. Rebitzer, G., Ekvall, T., Frischknecht, R., Hunkeler, D., Norris, G., Rydberg, T., Schmidt, W. P., Suh, S., Weidema, B.P., Pennington, D.W. (2004): "Life cycle assessment Part 1:Framework, goal and scope definition, inventory analysis, and applications". Environment International 30 (5)

14. ISO (1997): "ISO 14040 Environmental Management - Life Cycle Assessment - Principles and Framework"

15. Sobek, D.K., Ward, A.C. and Liker, J.K. (1999): “Toyota's Principles of Set Based Concurrent Engineering". Sloan Management Review 40

16. Ward, A.C., Shook, J.K. and Sobek, D.K. (2007): "Lean Product and Process Development". The Lean Enterprise Institute, Cambridge, Massachusetts

17. Cerri, D., Taisch, M., Terzi, S. (2012): "Multi-Objective Optimization of Product Life-Cycle Costs and Environmental Impacts". APMS conference 2012.

18. Garetti, M., Rosa, P., Terzi, S. (2012): "Life Cycle Simulation for the design of Product-Service Systems". Computers in Industry 63 